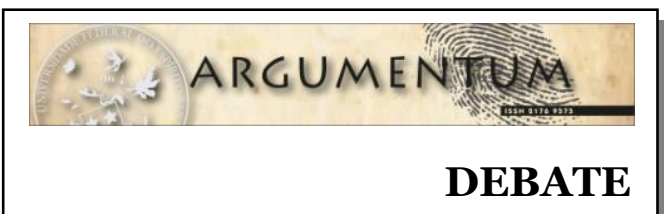

\title{
A segurança pública a partir de lentes interseccionais sobre raça, classe e gênero
}

\author{
Public security through intersectional lenses about race, class and gender
}

\section{Elaine PIMENTEL *}

https://orcid.org/0000-0003-2004-7968

\section{Palavras iniciais sobre o texto}

relação entre segurança pública e racismo está no cerne do texto de Andréa
Pires Rocha (2020), que se propõe a pensá-los como pilares sustentadores do
Estado burguês, proporcionando diversas reflexões acerca do capitalismo e das

Amparada em importantes referenciais teóricos da filosofia política, das ciências sociais, da literatura e da criminologia crítica, a autora transita entre categorias como singularidade, particularidade e universalidade, nas matrizes do materialismo históricodialético de Marx, para tecer uma severa crítica à sociabilidade burguesa e seus desdobramentos no campo da segurança pública, marcada pelo racismo estrutural. Dialoga, então, como os escritos de Michelle Alexandrer (2017), Magali da Silva Almeida (2014), Angela Davis (2018), Lélia González (1984), Silvio Almeida (2018), Abdias Nascimento (2016), Ana Flauzina (2008), Juliana Borges (2018), Alessandro Baratta (1999), David Garland (2014), Loïc Wacquant (2001; 2013), George Rusche e Otto Kirchheimer (2004), além de Erick Williams (2012), Frederick Engels (1984) e Lênin (2007), numa interessante interface teórica entre os estudos sobre raça e a criminologia crítica, que a leva à construção de sólidos argumentos em torno dos temas da segurança pública e do racismo.

O texto aponta elementos importantes para pensar o Estado capitalista como um Estado historicamente penal, sustentado pelo princípio burguês da segurança, que estabelece uma relação simbiótica com o racismo, opressão fortemente estruturada no capitalismo.

\footnotetext{
* Advogada. Doutora em Sociologia. Professora Adjunta do Curso de Graduação e Pós-Graduação (Mestrado) em Direito da Universidade Federal do Alagoas. (UFAL, Maceió, Brasil). Av. Lourival Melo Mota, S/N, Tabuleiro do Martins, Maceió - AL, CEP 57072-900. E-mail: elaine.pimentel@fda.ufal.br. Creative Commons Atribuição 4.0 Internacional (https://creativecommons.org/licenses/by/4.o/deed.pt_BR), que permite copiar e redistribuir o material em qualquer suporte ou formato, bem como adaptar, transformar e criar a partir deste material para qualquer fim, mesmo que comercial. O licenciante não pode revogar estes direitos desde que você respeite os termos da licença.
} 
Ultrapassando argumentos puramente teóricos e abstratos, a autora traz à lume dados estatísticos sobre o encarceramento no Brasil, em momentos distintos da história, para identificar, na realidade histórica do sistema punitivo brasileiro, a continuidade das práticas seletivas de segurança pública, que levam à prisão, principalmente, pessoas pobres e negras, retroalimentando, então, o racismo estrutural, numa sociedade dividida em classes, não somente pelas desigualdades sociais, mas também, e de forma inseparável, em razão das opressões de raça.

Os argumentos históricos e teóricos e os dados empíricos apresentados apontam para a compreensão, pela autora, de que o modelo capitalista de sociabilidade tende a criminalizar as classes subalternizadas, o que foi consolidado, em legislação penal do passado, por meio da criminalização de pobres e negros, de modo a proporcionar um verdadeiro controle penal das classes periféricas, no sentido atribuído por Giorgi (2013).

Os caminhos percorridos pela autora sustentam a afirmação de que o Brasil é um Estado penal e não Estado social, e que essa identidade resulta de uma escolha contextualizada na clássica encruzilhada entre socialismo e barbárie, realidade exasperada na atual crise sanitária da COVID-19, que chegou nas favelas e nas prisões, vitimando, em sua maioria, pobres e negros. Nega, então, a afirmação de que a pandemia atinge a todos pobres e ricos - indistintamente, já que o desemprego estrutural, a miséria e a fome produzem efeitos nefastos que se somam ao projeto genocida de pretos, pobres e indígenas, bem como de pessoas residentes em territórios sociais vulneráveis ou segregados em prisões.

O texto aborda, com amparo em Garland (2014) e Wacquant (2001), a relação da segurança pública com o Estado burguês, evidenciando que a ideologia política e econômica neoliberal leva ao desmonte da proteção social conquistada, em nome da economia, o que abre caminhos para que a segurança pública se torne a principal via de controle dos pobres e das classes subalternizadas.

Com o propósito de demonstrar a força das opressões de raça sobre a segurança pública no Brasil contemporâneo, a autora retoma percursos históricos da escravidão, associando-a ao encarceramento em massa, fenômeno sociopolítico que não pode ser compreendido fora de uma análise de elementos como raça, classe e gênero.

\section{A interface entre raça, classe e gênero: segurança pública a partir de reflexões interseccionais}

A escrita de Andrea Rocha trilha caminhos e suscita reflexões sobre o racismo que nem sempre estão em evidência nos estudos sobre segurança pública, sobretudo quando as políticas públicas de segurança são pensadas como atos de governança fundadas exclusivamente em dados numéricos, sem aprofundamento analítico acerca dos seus principais destinatários. Afinal, como afirma no texto, por se tratar de política indissociável da política econômica, posta na ordem do capital, a segurança tende a se materializar como segurança econômica - destinada a proteger os grandes capitais -, e como segurança pública, cujo propósito é resguardar propriedade e proprietários. 
Essa reprodução da lógica excludente do capitalismo, que está nas bases da escravidão - a propriedade da terra e das pessoas negras - é uma realidade que por muito tempo foi negligenciada, tanto na construção de políticas públicas como na produção acadêmica. Nesse sentido, as contribuições teóricas do feminismo negro, contempladas no texto por meio dos escritos de Lélia Gonzáles (1984), Angela Davis (2018) e Juliana Borges (2018), trouxeram elementos para pensar essa estrutura de múltiplas opressões com atenção, também, às relações de gênero, presentes nas bases da estrutura social e política do patriarcado, que caminha lado a lado com o capitalismo. Assim, para além da raça e classe, o patriarcado se sustenta no sentido mais amplo de propriedade privada: aquela que envolve as terras, os escravos e escravas e as mulheres e crianças.

Heleieth Saffioti (2004) apresenta ponderações relevantes, ao tratar sobre o patriarcado, afirma que "[...] o direito patriarcal perpassa não apenas a sociedade civil, mas impregna também o Estado" (SAFFIOTI, 2004, p. 54). Assim, é possível perceber, na atuação estatal no campo da segurança pública, ao longo da história, a forte presença da estrutura patriarcal, em diversos aspectos. Primeiro, na ocupação dos espaços de poder e decisão, majoritariamente com presenças de homens brancos, oriundos das classes economicamente privilegiadas. Segundo, no contingente das forças de segurança, com a presença mais substancial de homens do que mulheres, mas com diferentes cargos ou gradações hierarquizadas, de modo que homens brancos ocupam mais frequentemente, também, os topos das hierarquias intermediárias do que homens negros e mulheres. Para mulheres negras, então, são menores as possibilidades de tomada de decisão nesses espaços. Essa subalternidade estrutural impacta na forma como são pensadas e executadas as políticas de segurança pública, alheias a condições sociais, de raça e de gênero.

No Brasil, o pensamento feminista negro está atento a essa realidade histórica de opressões que se somam, criando abismos entre as pessoas, não apenas nas relações pessoais e intersubjetivas, mas também e muito fortemente, na relação entre homens e mulheres com o Estado e seu poder punitivo, marcado por forte seletividade. É nesse sentido que os escritos de Sueli Carneiro (2011) problematizam a estreita relação entre racismo, sexismo e desigualdade.

Sueli Carneiro, filósofa e militante negra, afirma com veemência que “[...] pobreza tem cor no Brasil” (CARNEIRO, 2011, p. 57). Ressalta que "[...] a crescente compreensão sobre a identidade entre raça e pobreza no Brasil e na América Latina vem sendo objeto de atenção das agências internacionais de cooperação" (CARNEIRO, 2011, p. 50). Esse recente olhar sobre a desigualdade social e as opressões de raça, demonstra que estamos diante de verdadeiros legados históricos nefastos, que não receberam o devido reconhecimento, tanto no cenário internacional, como no Brasil. O silêncio sobre eles é mais uma forma de negar a realidade histórica, o que apenas fortalece o racismo estrutural, como evidenciam os escritos de Lélia González (2011):

Nosso empenho, portanto, se dá no sentido de que a sociedade brasileira ao refletir sobre a situação do seguimento negro que dela faz parte (daí a importância de ocupar todos os espaços possíveis para que isso suceda) possa voltarse sobre si mesma e reconhecer nas suas contradições internas as profundas desigualdades raciais que a caracterizam (GONZÁLEZ, 1984, p. 12).

Argum., Vitória, v. 12, n. 3, p. 26-34, set./dez. 2020. | ISSN 2176-9575 
Essas contradições, sobre as quais trata Gonzáles, estão imbricadas nas estruturas do capitalismo, de modo que reflexões em torno de quaisquer políticas e práticas do Estado - e mais fortemente no campo da segurança pública - não podem prescindir de uma aproximação à realidade do racismo, do sexismo e da desigualdade, com afirma Andrea Rocha em seu texto.

O debate sobre a relação entre múltiplas opressões fez crescer no cenário acadêmico e político brasileiro o conceito de interseccionalidade. Embora o termo não apareça na escrita de Andrea Rocha, é importante tecer algumas reflexões a respeito, diante da proximidade que enseja à abordagem da autora.

A expressão interseccionalidade, na forma como vem sendo trabalhada no Brasil, segue os caminhos analíticos de Kimberlé Crenshaw (2002), que identifica a existência do que chama de invisibilidade interseccional, subordinação interseccional e discriminação interseccional, não analisadas adequadamente pelas perspectivas tradicionais acerca das opressões de gênero ou raça.

Quando certos problemas são categorizados como manifestações da subordinação de gênero de mulheres ou da subordinação racial de determinados grupos, surge um duplo problema de superinclusão e de subinclusão (CRENSHAW, 2002, p. 174).

Assim, Crenshaw faz uso do termo interseccionalidade, admitindo tratar-se de conceituação metafórica, para explicá-la como “[...] uma conceituação do problema que busca capturar as consequências estruturais e dinâmicas da interação entre dois ou mais eixos da subordinação" (CRENSHAW, 2002, p. 177). Isso significa que não somente raça, classe e gênero estão contemplados na ideia de interseccionalidade, mas também toda e qualquer opressão - étnica, geracional, de orientação sexual, de origem geográfica, entre outras - que podem ser identificadas nas singularidades das experiências dos sujeitos na vida social.

No Brasil, em que pese a ancestral referência às aproximações entre gênero, raça e classe como elementos analíticos para a compreensão da realidade social, nos escritos de Lélia Gonzáles (1984), Sueli Carneiro (2011), e outras feministas negras, o conceito de interseccionalidade, inspirado em Crenshaw, vem sendo utilizado mais recentemente como ferramenta epistemológica para a interpretação das práticas sociais e interpretação de dados sobre violências, evidenciando a necessidade de estreitamento entre estudos sobre racismo e desigualdade social no contexto dos feminismos. É assim que Carla Akotirene (2018) aborda o tema, considerando o termo como mecanismo apto a impedir reducionismos da política de identidade (AKOTIRENE, 2018, p. 54).

Esse esforço de demarcar o conceito de interseccionalidade, porém, resulta das reivindicações de feministas negras, em seus escritos e seus espaços de fala, diante da hegemonia do feminismo de matriz liberal, considerado pelo feminismo negro como feminismo branco, que não trazia em suas demandas por igualdade, a demarcação da raça como fator de opressão significativo. Gonzáles, inclusive, ressalta o silêncio histórico do feminismo - tanto na dimensão acadêmica, quanto na prática em movimentos soci- 
ais - sobre o racismo e a tendência a elevar as opressões de gênero ao centro capitalismo patriarcal, como se fossem independentes das opressões de raça.

\footnotetext{
Cabe, então, a pergunta: como se explica este 'esquecimento' por parte do feminismo? A resposta, na nossa opinião, está no que alguns cientistas sociais caracterizam como racismo por omissão e cujas raízes, dizemos nós, se encontram em uma visão de mundo eurocêntrica e neo-colonialista da realidade (GONZÁLEZ, 2011, p. 13).
}

É dessa perspectiva que resultam os esforços de pensar o racismo, o sexismo e as desigualdades de classe no contexto das realidades sociais e históricas brasileiras e não a partir das experiências de outros países, sobretudo os da Europa e os Estados Unidos.

Mas em aspectos essas questões se relacionam com a segurança pública, nos termos em que Andrea Rocha aborda o tema? É justamente no reconhecimento de que as políticas de segurança são alheias às vivências dos sujeitos pobres e negros, homens e mulheres, no contexto sócio-político e opressor do Estado burguês, cujo aparato repressivo é estruturado em nome da proteção à propriedade e à liberdade, mas que, contraditoriamente, atinge grupos sociais de forma seletiva, obedecendo a padrões discriminatórios de raça, classe e gênero.

Por isso, os dados apresentados e problematizados por Andrea Rocha sobre o encarceramento em massa no Brasil, têm muito a dizer a respeito da lógica implícita nas estruturas do capitalismo patriarcal, que faz do Brasil um Estado penal.

\section{Racismo e encarceramento em massa no Brasil}

O termo encarceramento em massa foi incorporado ao discurso criminológico em todo o mundo. No entanto, será que o esse fenômeno sócio-político produz iguais efeitos em todas as partes do mundo?

Autores como David Garland (2001), Silva Sanchez (2013) e Loïc Wacquat (2013) transitam por essa expressão, considerando, sobretudo, o contexto social, político e econômico da Europa e da América do Norte. As reflexões partem da observação de dados oficiais sobre encarceramento em países como Inglaterra, Espanha, França e Estados Unidos nas últimas décadas, cujo crescimento acelerado e sistemático leva à compreensão de que não se trata de fenômeno isolado em um determinado país, mas uma tendência mundial de controle penal das classes consideradas perigosas ou, em outra perspectiva, das classes subalternizadas, preponderantemente formadas por pobres e negros, principais destinatários das forças de segurança pública.

No esforço de compreender o encarceramento massivo a partir da realidade brasileira, Juliana Borges (2018) aborda o tema com profundidade, na obra O que é encarceramento em massa?, citada por Andréa Rocha em seu texto.

Borges parte de um conjunto de questionamentos relevantes para problematizar o crescimento dos índices de aprisionamento no Brasil nas últimas décadas:

Argum., Vitória, v. 12, n. 3, p. 26-34, set./dez. 2020. | ISSN 2176-9575 
De onde e com quais motivações se estrutura este sistema de justiça criminal como conhecemos hoje? Como se estabelece crime e criminoso? Como e sob quais interesses se define o que deve ser tornado ilegal e criminalizado? Por que continuamos insistindo em uma instituição que, a todo momento, a sociedade grita que está em crise? Qual a ideologia que está por detrás deste gigantesco complexo que se expande e se aprofunda no mundo todo? Por que, de forma tão abrupta, os índices de encarceramento feminino passam a crescer? Por que são as populações negras e indígenas - estes últimos com pouquíssimos dados sobre sua situação carcerária - as mais afetadas por este complexo prisional? (BORGES, 2018, p. 21).

Sem a pretensão de esgotar o tema, Borges enfrenta esses diversos aspectos sobre o sistema punitivo brasileiro, em diálogo com a intelectualidade e o ativismo negros. Isso porque enfatiza que o encarceramento em massa está intimamente ligado ao racismo estrutural que compõe as bases do sistema de justiça criminal, sendo este entendido, aqui, como todo o aparato policial, judicial e carcerário, que precisa ser pensado em conjunto para se entender o problema do encarceramento massivo.

Todavia, quando se fala sobre encarceramento em massa, não se deve tomar o sistema carcerário como ponto de partida, mas sim como aparato final do sistema punitivo, já que o encarceramento é prática iniciada nas trilhas da segurança pública e na seletividade resultante de múltiplas opressões, que precisam ser pensadas de forma interseccional. No texto de Andrea Rocha, o foco é o racismo como elemento-chave para se compreender práticas opressoras da segurança pública, de modo que, juntos - racismo e segurança pública -, sustentam o Estado burguês. A autora concorda com Vera Malagutti Batista (2014), quando afirma que as demandas por recrudescimento punitivo e a seletividade dos destinatários do sistema penal são "[...] permanências históricas" (BATISTA, 2014, . 135). Encontra também em Rusche e Kirchheimer (2004) o suporte criminológico para compreender a intrínseca relação existente entre as formas punitivas e as relações de produção, determinadas pelo que chama de forças sociais, oriundas das esferas econômicas e fiscais, de modo que as prisões, no contexto do capitalismo, surgem como mecanismos para controlar o proletariado.

A grande questão, subjacente a esse importante apanhado criminológico, no texto de Andrea Rocha, é: que classes compõem o proletariado a ser controlado penalmente?

A resposta se encontra nos dados apresentados pela autora, que revelam não somente o crescimento carcerário no Brasil nas últimas décadas, mas, principalmente, o perfil socioeconômico e racial das pessoas presas, bem como os tipos de crimes que mais levam pobres e negros à prisão. São crimes contra o patrimônio e o tráfico de drogas numa política de guerra às drogas, que é uma guerra contra as classes subalternizadas, ou seja, pobres e negros, como afirma Borges (2018) -, o que evidencia os impactos do Estado capitalista neoliberal na administração e controle penal das classes ditas perigosas, de modo que a segurança figura como instrumento repressivo racista e seletivo.

\section{Considerações finais}

O texto de Andréa Pires Rocha provoca reflexões em vários sentidos. Primeiramente, por tomar a realidade histórica do Brasil como referência inescapável para demonstrar

Argum., Vitória, v. 12, n. 3, p. 26-34, set./dez. 2020. | ISSN 2176-9575 
a força do racismo estrutural nas dinâmicas da sociedade brasileira. Em seguida, por demonstrar como a segurança pública serve ao Estado burguês, de modo a reforçar o abismo existentes entre classes sociais, não se restringindo às desigualdades econômicas, pois encontra no racismo - legado nefasto da escravidão - a força para exercer o controle penal sobre as classes subalternizadas, de forma seletiva.

Os argumentos apresentados pela autora se amparam em dados estatísticos sobre o encarceramento no Brasil, que comprovam o fenômeno sociopolítico do encarceramento em massa, resultado do controle penal exercido sobre as classes periféricas pobres e negros -, o que faz do país um verdadeiro Estado penal.

O amplo diálogo teórico presente no texto demonstra o cuidado intelectual da autora de buscar fundamentos na filosofia política, nas ciências sociais e na criminologia, para desvelar a relação intrínseca entre segurança em racismo como pilares sustentadores do Estado burguês, sem desconsiderar a possibilidade de influência interseccional de outras opressões, a exemplo das de gênero, a alimentar verdadeiro capitalismo patriarcal.

A escrita de Andrea Rocha Pires revela não apenas o seu vasto e profundo conhecimento acerca desse complexo tema, mas também a grande sensibilidade social, que a permite abordar segurança e racismo para além de questionamentos abstratos. Seu olhar sobre a realidade do racismo estrutural e das violências praticadas pelo Estado contra pobres e negros consiste em importante contribuição acadêmica para o fortalecimento das vias de superação das contradições do Estado penal, que caminha de mãos dadas com o capitalismo.

\section{Referências}

ALEXANDER, Michelle. A nova segregação: racismo e encarceramento em massa. Tradução de Pedro Davoglio. São Paulo: Boitempo, 2017.

ALMEIDA, Magali da Silva. Desumanização da população negra: genocídio como princípio tácito do capitalismo. Em Pauta, Rio de Janeiro, n. 34, v. 12, p. 131- 154, jul./dez. 2014.

ALMEIDA, Silvio. O que é racismo estrutural? Belo Horizonte: Letramento; Justificando, 2018. (Série Feminismos Plurais. Coord. Djamila Ribeiro).

AKOTIRENE, Carla. O que é interseccionalidade. Belo Horizonte: Letramento, 2018.

BARATTA, Alessandro. O paradigma do gênero: da questão criminal à questão humana. In: CAMPOS, Carmen Hein (Org.). Criminologia e Feminismo. Porto Alegre: Editora Sulina, 1999.

BATISTA, Vera Malaguti. O medo na cidade do Rio de Janeiro: dois tempos de uma história. 2. reimp. Rio de Janeiro: Revan, 2014.

Argum., Vitória, v. 12, n. 3, p. 26-34, set./dez. 2020. | ISSN 2176-9575 
BORGES, Juliana. O que é encarceramento em massa. Belo Horizonte: Letramento, 2018.

CARNEIRO, Sueli. Racismo, sexismo e desigualdade no Brasil. São Paulo: Sele negro, 2011. (Consciência em Debate/Coordenadora Vera Lúcia Benedito).

CRENSHAW, Kimberlé. Documento para o encontro de especialistas em aspectos da discriminação racial relativos ao gênero. Rev. Estud. Fem., Florianópolis, v. 10, n. 1, 2002. Disponível em: http://www.scielo.br/scielo.php?pid=So104026X2002000100011\&script=sci_abstract\&tlng=pt. Acesso em: 14 jun. 2020.

DAVIS, Angela. Estarão as prisões obsoletas? Tradução de Marina Vargas. 1. ed. Rio de Janeiro: Difel, 2018.

ENGELS, Frederick. A Origem da Família, da Propriedade Privada e do Estado. Rio de Janeiro: Civilização Brasileira, 1984.

FLAUZINA, Ana Luiza Pinheiro. Corpo negro caído no chão: o sistema penal e o projeto genocida do Estado brasileiro. Rio de Janeiro: Contraponto, 2008.

GARLAND, David. A cultura do controle: crime e ordem social na sociedade contemporânea. Rio de Janeiro: Revan, 2014.

GARLAND, David. Mass imprisonment: social causes and consequences. London: Sage Publications Ltd, 2001.

GIORGI, Alessandro De. A miséria governada através do sistema penal. Rio de Janeiro: Revan; ICC, 2013.

GONZÁLES, L. Racismo e sexismo na cultura brasileira. Revista Ciências Sociais Hoje, Anpocs, p. 223-244, 1984.

LÊNIN, V. I. O Estado e a Revolução: o eu ensina o marxismo sobre o Estado e o papel do proletariado na revolução. [tradução revista por Aristiides Lobo] 1. ed. São Paulo: Expressão Popular, 2007.

NASCIMENTO, Abdias. O genocídio do negro brasileiro: processo de um racismo mascarado. 3. ed. São Paulo: Perspectivas, 2016.

RUSCHE, Georg; KIRCHHEIMER, Otto. Punição e Estrutura Social. 2. ed. Rio de Janeiro: Revan, 2004.

SILVA SANCHEZ, Jesús-María. A expansão do direito penal: aspectos da política criminal nas sociedades pós-industriais. 3. ed. rev. e atual. Tradução de Luiz Otávio e Oliveira Rocha. São Paulo: Revista dos Tribunais, 2013. 
SAFFIOTI, Hekeieth I. B. Gênero, patriarcado e violência. São Paulo: Fundação Perseu Abramo, 2004.

WACQUANT, Loïc. As prisões da miséria. Tradução de André Telles. Rio de Janeiro: Jorge Zahar, 2001.

WACQUANT, Loïc. Punir os Pobres: a nova gestão da miséria nos Estados Unidos. Tradução de Sérgio Lamarão. 1. ed. reimp. Rio de Janeiro: Revan, 2003. agosto de 2007.

WILLIAMS, Eric. Capitalismo e Escravidão. Trad. Denise Bottmann; Prefácio Rafael de Bivar Marques. São Paulo: Companhia das Letras, 2012.

\footnotetext{
Elaine PIMENTEL

Doutora em Sociologia pela Universidade Federal de Pernambuco (2011). Mestra em Sociologia pela Universidade Federal de Alagoas (2005). Graduada em Direito pela Universidade Federal de Alagoas (1999). Professora Adjunta do Curso de Graduação e Pós-Graduação (Mestrado) em Direito da Universidade Federal de Alagoas. Tem experiência em atividades de pesquisa e extensão nas áreas Direito e Sociologia, com ênfase em Criminologia, atuando principalmente nos seguintes temas: feminismo, gênero, segurança pública, sistema punitivo, violência, criminalidade. É líder dos grupos de pesquisa CARMIM Feminismo Jurídico, Núcleo de Estudos e Políticas Penitenciárias (NEPP), Vice-líder dos grupos de pesquisa Núcleo de Estudos sobre a Violência em Alagoas (NEVIAL) e Grupo de Pesquisa Educações em Prisões (GPEP), todos registrados no CNPq. É Diretora da Faculdade de Direito de Alagoas, da Universidade Federal de Alagoas (2018-2022) e voluntária na ONG Centro de Defesa dos Direitos da Mulher (CDDM).
} 